\title{
Design of an Ecological Immigrant Compensation Program for China's Nature Reserves
}

\author{
Xiao-yan WEI \\ Institute of Panchen Lama \\ Qinghai Normal University \\ Xining, China \\ e-mail: weixiaoyan4477@163.com
}

Feng-gui LIU

Key Laboratory of Qinghai-Tibetan Plateau Resources

and Environment

Qinghai Normal University

Xining, China

e-mail: liufenggui@igsnrr.ac.cn

\author{
Xu-feng MAO* \\ Key Laboratory of Qinghai-Tibetan Plateau Resources \\ and Environment \\ Qinghai Normal University, Xining, China \\ e-mail: maoxufeng@yeah.net
}

\begin{abstract}
Reasonable ecological compensation is about efficiency, equity and sustainable development of nature reserves in China. A large quantity of cases on ecological migrant's compensation in various nature reserves of China was utilized to summarize the main program, contents and methods of ecological compensation of nature reserves in China. Some issues in different compensation stages were discussed to get a more scientific design. The current study may provide new ideas for ecological compensation for the ecocompensation with nature reserves in China.
\end{abstract}

Keywords-Nature reserves; Ecological compensation; Program design

\section{INTRODUCTION}

Nature reserves of different types provide a guarantee for ecological and environmental safety[1]. However, ecological immigrant compensation for the construction of nature reserves in China has been crippled by a lack of theoretical and practical guidance and ecological compensation is a troublesome issue at present[2].

Ecological immigrant compensation of the nature reserves has its unique features as compared with other immigration policies[3]: (1) Difficulty in clearly defining the participants receiving compensation; (2) Greatly diverse and unquantifiable loss and hence the compensation for the immigrants; (3) Long cycle of compensation; (4) great impact from local culture, custom and religious belief. Thus to devise an ecological immigrant compensation system reasonably and to ensure the sustainable development of the nature reserves, it is important to learn from the experiences of other compensation and make innovations.

In the absence of an established set of standards and procedures, ecological compensation contains high arbitrariness. Based on a summary of the ecological compensation cases of China's nature reserves, we come up with the differences and similarities as compared with other types of ecological compensation. We tentatively proposed a design of ecological immigrant compensation system of the nature reserves so as to provide inspirations for the ecological compensation practice.
II. OVERALL DESIGN OF AN ECOLOGICAL IMMIGRANT COMPENSATION SYSTEM OF THE NATURE RESERVES

Nature reserves may differ greatly in the ecosystem, which includes forest, desert and wetland. Given to large disparities in the natural and social environment, there is rarely a unified set of standards and procedures of ecological compensation[4]. Whatever the ecosystem, ecological compensation for the immigrants should consider the following aspects: firstly, contributions made by the immigrants, and secondly, immigrants' loss. Immigrants' relocation is of high ecosystem service value and facilitates the ecosystem restoration. Loss, on the part of the immigrants, mainly refers to the loss of fixed assets, opportunity cost and social capital. However, the actual standards and procedures of compensation depend on the local economic development level combined with considerations of natural and social factors. Several methods are now in use for determining the standards and procedures of compensation, such as willingness investigation, market value investigation and opportunity cost estimation [5-7].

By analyzing the commonality across ecological compensation cases, we proposed a general design of ecological immigrant compensation system, which consists of four stages: the first is the preparation stage, during which large amount of data are collected; the second is the planning stage, during which the participants receiving the compensation and compensation standards and procedures are determined; the third is the implementation stage, during which the compensation is implemented in accordance with the standards; the fourth is the assessment stage, which is intended for assessing the compensation effect, identifying defects and formulating the countermeasures.

\section{RESEARCH CONTENTS AND METHOD FOR EACH STAGE OF ECOLOGICAL COMPENSATION}

\section{A. The preparation stage}

The preparation stage mainly involves the collection of data related to ecological compensation, which is divided 
into four types: the first is the basic information of the nature reserves; the second is local social and economic background; the third is the information of the stakeholders, including local residents, immigrants and managerial personnel; the fourth is the relevant rules, policies and regulations concerning ecological compensation. Data of different types can be collected by literature review, field survey and questionnaire survey[8], as illustrated in Table 1.

Data collection should be based on a full awareness of disparities across the ecosystems, which usually displays large variations in provisioning, supporting, regulating and cultural services[9,10]. The ecological services most pertinent to local production and livelihood will be the focus of discussion, and a careful analysis paves the way for ecological compensation accounting[11]. Take three typical ecosystems, grassland, forest land and wetland, as an example. These three ecosystems are associated with different immigrants' loss and contribution[12-19]. For the grassland, the major ecological services are provisioning of pasture plants, mutton and beef[12-13]. Forest land's main ecological services are provisioning of food, fuels, raw materials and forest tourism[14-18]. Wetland's main ecological services are provisioning of fish, wetland plants and wetland tourism[19-25].

TABLE I. TYPES, CONTENTS AND COLLECTION METHOD OF DATA

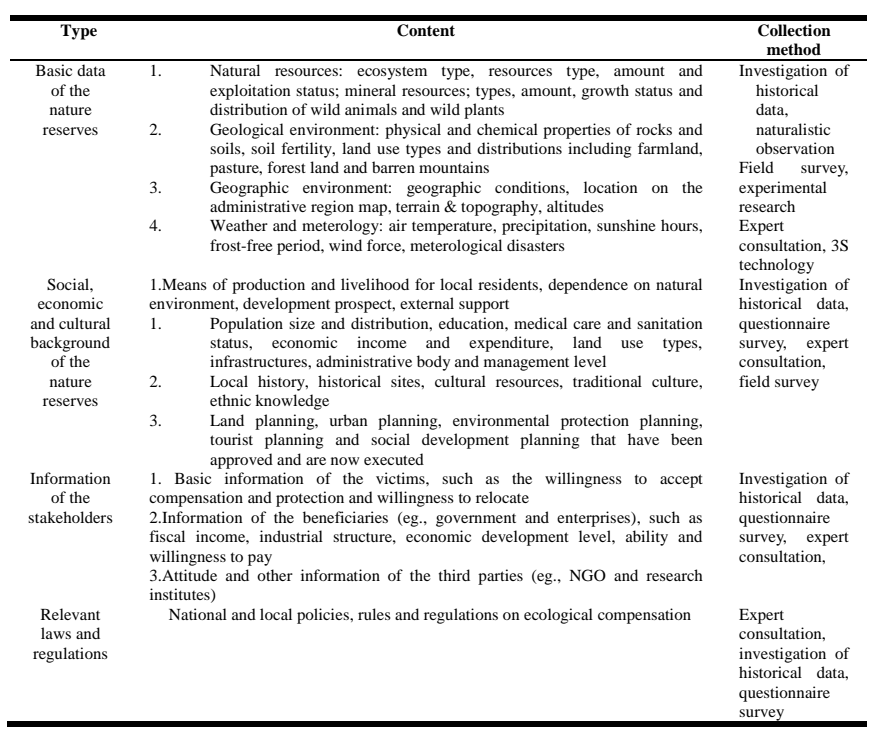

Advantages and disadvantages of each data collection method are taken into account and applied with discretion for different situations. Investigation of historical data has low cost, but lacks in timeliness. Naturalistic observation is more objective and intuitive, but labor- and time-consuming. Field survey can acquire the latest and objective data, but is also labor- and time-consuming. Experimental research provides accurate and scientific data, but it may be restrained by lack of equipments and skills. Expert consultation is easy and direct, but contains considerable subjectivity. 3S technology can acquire large-scale data very quickly, but further verification and analysis will be needed on a smaller scale.

\section{B. The planning stage}

The planning stage is the most important of the four stages as the standards and procedures of ecological compensation are determined at this stage through technical means. Immigrants' loss and contribution are the major contents of accounting to determine the compensation standards. The accounting methods and the features of each method are shown in Table 2.

Different accounting methods can be used depending on distinctive local natural and social background. Then by comparing the results of different accounting methods, the most accurate one can be chosen. Besides the compensation standards, the specific procedures and length of compensation are also to be determined along with proposals of safeguard measures on the fiscal, material, policy and legal levels. That is to say, the institutional, policy, legal and fiscal measures[27,28] should be grounded in the comprehensive consideration of local economic development, payment ability, and social culture[29]. Willingness of ethnic minorities to relocate and to be involved in the ecological protection of the nature reserves can be mobilized by resorting to the minority cultural folklore and heritage that encourages ecological protection, sustainable use of natural resources and efforts to increase the income. The benefits are two-fold: firstly, it mobilizes the ethnic minorities' enthusiasm to be involved, and secondly, it helps protects minority culture[30].

TABLE II. METHODS FOR ACCOUNTING OF COMPENSATION STANDARDS AND THE ADVANTAGES OF EACH METHOD

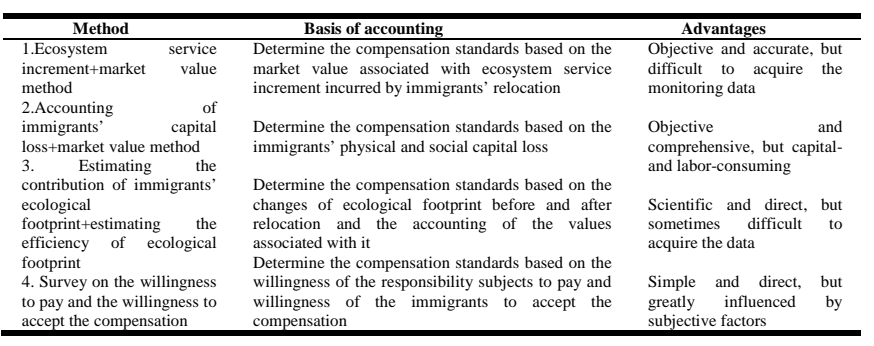

\section{THE IMPLEMENTATION STAGE}

The implementation stage is the stage of enforcing the compensation standards through laws, regulations and policies under coordination between different government departments.

Building the information disclosure mechanism and holding public hearings on the compensation standards and procedures are effective measures to win public acceptance and support. Information such as the destinations of the compensation capitals and supplies can be disclosed via this mechanism regularly so as to mobilize the general public to get involved in the construction and perfection of the compensation system.

Moreover, sufficient communication and coordination between the immigrants, managerial personal of the nature reserves, local residents and the general public via unobstructed channels are indispensable for ensuring the 
equity and transparency of compensation implementation. That is, ensuring that the compensation capitals and supplies are received by the "right people".

A multi-channel supervisory mechanism is another important aspect of implementation. An auditing mechanism can be built and operated in parallel with inquires and exchange visits among the people receiving the compensation and working staff of the responsible authorities.

A market-based mechanism for ecological compensation will be the new orientation. Compensation funds, subsidies, guarantee payment (refunded after meeting the ecological requirements) and donations can all be the concrete forms of the market-based operation [31]. Any valuable experiences and lessons should be summarized for institutionalization and standardization of ecological compensation, providing reference for ecological compensation in other districts.

\section{THE ASSESSMENT STAGE}

The assessment stage, which is the final stage, consists of the following contents: firstly, assessing the compensation effect; secondly, assessing the development of the immigrants after relocation; thirdly, doing cost-benefit analysis of the ecological compensation.

Technologies such as remote sensing, GIS and GPS will provide considerable benefits for assessing the compensation effect. Building ecological monitoring and GIS platform can greatly facilitate the assessment of ecological environment changes, ecosystem structure, ecological functions, ecological sensitivity, resources and environment carrying capacity and ecosystem restoration. This will further promote the implementation assessment of major ecological projects, creation of ecosystem service evaluation system and performance evaluation system, improvement of database and information inquiry system and finally the sharing of information resources.

Suitability of immigrants' production and livelihood after relocation should be also assessed [32-35], by focusing on the following contents: living standards, income level, changes of living environment, building of a new social relation network, reconstruction of traditional customs and cultural transitions. The effects of various support measures (eg., policies, projects, industries, and training) are also assessed to monitor the infrastructure construction of the resettlement area, ensure social harmony and stability and increase immigrants' income.

The cost-benefit analysis of ecological compensation is based on an input-output comparison. The input terms mainly include the capital investment for the early and middle stage of relocation and for subsequent development of the resettlement area. Outputs included into the accounting are changes in ecosystem service values before and after immigration and social benefits of immigration.

\section{CONCLUSIONS}

We analyzed the commonality and individuality of ecological compensation of nature reserves in China as compared with other types of ecological compensation based on existing achievements. Then general procedures of ecological compensation of nature reserves were proposed. The disparities of ecological compensation of nature reserves mainly consist in the stakeholders, contents and time length of compensation. By reviewing different cases, we put forward the issues deserving attention for each stage of ecological compensation. We hope that our findings from this general analysis will shed new light onto the ecological compensation work in China.

\section{ACKNOWLEDGMENT}

This work was supported by National Social Science Foundation (14CJY011) and Qinghai Social Science Foundation(14014).

\section{REFERENCES}

[1] X.N.Zhang, Z.X. Wang and X.W. Xie, ”Discussions on Protecting Economic Benefit of Community in Nature Reserves,"Chinese Agricultural Science Bulletin,Vol.23,May.2007,pp.546-551.

[2] C.M.Chen,"Ecological Compensation Mechanism in Wuyishan National Nature Reserve of Fujian Province,"China.Scientia Geographica Sinica,Vol.31, May.2011,pp.2011594-599.

[3] X.Y. Wei, X.F. Mao and J.X.Xia ,’Discussion on Eco-compensation Standards for Nature Reserves in China,"World Forestry Research,Vol.26,Apr. 2013,pp.76-81.

[4] Sachurina,"The Overall Framework Design of the Ecological Compensation Mechanism in Minority Areas of China,"Guangxi Ethnic Studies,Vol.3,Qct.2011,pp.162-166.

[5] G.zh.He,Y.L.Lv,X.L.Wang and J.Y. Han,”Contingent valuation method in governmental environmental auditing-case of Wuli Lake, Wu xi City, China," Acta Ecologica Sinica ,Vol.27,Jan.2007,pp.270280

[6] Zh.Q.Zhang,Zh.M.Xu,A.H.Long and Z.T. Gong,"Measuring the economic value of restoring ecosystem services in Zhang ye city of Hei he river basin-Comparison and application of continuous and discrete contingent valuation survey,”Journal of Natural Resources, Vol.19,Mar.2004, pp.230-239.

[7] X.G.Li, H.Miao,H.Zheng, Zh.Y. Ou Yang, and Y. Xiao,”Application of opportunity-cost method in determining ecological compensation standard: a case study in the central mountainous area of Hainan Island,”Acta Ecologica Sinica,Vol.29,Sep.2009,pp.4875-4883.

[8] Q.W.Min ,L.Zhen and G.M. Yang,"Progress of Researches and Practices of Ecological Compensation of Nature Reserves,"Journal of Ecology and Rural Environment, Vol.23,Jan.2007,pp.81- 84.

[9] Ch.H.Wang, Y.L. Wen, Ch.D .Hu and K.Ch. Si,”Research Progress on Harmonious Development of Nature Reserves and Surrounding Communities,"Issues of Forestry Economics,Vol.30,Dec.2010,pp.6975.

[10] K.Li,Y.X.Chen,L.J.Chen and Ch.M.Ch,"Research Progress on Ecological Compensation Mechanism of Domestic Nature Reserve, "Heilongjiang Agricultural Sciences,Vol.3,Mar:2011,pp.133-136.

[11] X.Y.Wei and J.X.Xia,"Ecological compensation for large water projects based on ecological footprint theory; a case study in China.,"Procedia Environmental Sciences,Vol.1,Nov.2012,pp.13381345.

[12] F.X.Huang, M.Y. Kang and X.Sh. Zhang,"The Economic Compensation Strategy in the Process of Turning Cultivated Land Back Into Forests and Grasslands (TCFG) ,’Acta Ecologica Sinica, Vol.22,Apr.2002,pp.471-478.

[13] G.M.,Yang,Q.W.Min,W.H.Li,L.Liu,Q.W. Rong and X.B.Wu, "Herdmen's willingness to accept(WTA) compensation for implement of prohibiting-graze policy in Xilingguole steppe,"Ecology and Environment, Vol.15,Jun.2006,pp.747-751. 
[14] H,Y.Feng,"Accounting the forest ecological benefit and the path of it's compensation,"Changchun:Northeast Normal University,Sep.2010,pp.23-32

[15] W.H.Li, F.Li, Sh.D. Li and M.Ch. Liu, "Discussions on Several Issues of Forest Eco-compensation Mechanism,"China Population Resources and Environment, Vol.17,Feb.2007,pp.13-18.

[16] L.Wang, Y. Su and G.F. Cui,"Quantitative Study on the Ecological Compensation for Nature Reserves Based on the"Virtual Land"Method,"Journal of Natural Resources,Vol.26,Jan.2011,pp.3447.

[17] Sh.Zh.Lu ,'Discussion on Ecological Compensation of Involving Construction Project in Nature Conversation Area of Guangxi,”Guangxi Forestry Science,Vol.36,Apr.2007,pp.223-227.

[18] Ch.M. Chen, "Ecological Compensation Mechanism in Wuyishan National Nature Reserve of Fujian Province,”Scientia Geographica Sinica,Vol.31,May.2011,pp.594-599.

[19] X. F. Mao, X. Y.Wei and J.X. Xia, "Evaluation of ecological migrants' adaptation to their new living area in Three-River Headwater wetland,"China.Procedia Environmental Sciences,Vol.13,Nov.2012,pp.1346-1353.

[20] Y.G Xie and R. Jiang,"Analysis of the Compensation Mechanism of the Cost of Ecological Water in Wetland Reserve-A Case Study of Zhalong Wetland in Heilongjiang Province,"Seeking Truth, Vil.33,Jan.2006,pp.67-72.

[21] T.Wang, L.S. Wang and M. Jiang,"’Research on calculating system of ecological compensation standard for reservoir basin: A case of Dahuofang reservoir basin,"Ecology and Environmental Sciences, Vol.19,Jun.2010,pp.1439-1444.

[22] L.Y.Xu,Zh.F.Yang,L.Shuai, J.Sh.Yu and Sh.L. Liu, "Ecocompensation of Reservoir Project based on Ecosystem Service Function Value,"China Population Resources and Environment,Vol.16,Apr.2006,pp.125-128.

[23] W.M.Cai,Sh.Y.Yang, S.Y.Wang and N. Zhou,”A Study on Externality Problems and Countermeasures of Establishing Wetlands Nature Reserve:Take Tianjin Qilihai Wetland as an Example,”Journal of Chongqing University(Social Science Edition),Vol.16,Jun.2010,pp.10-15.

[24] Sh.L. Chen and H. Guan,"Study on Ecological Compensation of Yancheng Wetland Natural Protection Zone in Jiangsu,"Journal of Hainan Normal University(Natural Science), Vol.2,Feb.2012,pp. 216220.
[25] X.Y Wei, J.X. Xia and Y.H. Wu ,"Ecological Compensation Criteria for Ecological Migrations of water Transfer Projects Based on Ecological Footprint Theory,"Research of Soil and Water Conservation,Vol.19,May.2012,pp.214-218.

[26] Y.Wang and,J.P.Yan,Research of Soil and Water Conservation.Chinese Rural Economy,Chinese Rural Economy,Jan.2010,pp.63-68.

[27] Zh.P. Yang ,"Analysis of the Ecological Compensation Based on Ecological Footprint Change in Elk Nature Reserve of Yancheng,"Research of Soil and Water Conservation,Vol.18,Feb.2011,pp.261-264.

[28] D.F.Feng, Y. Ren, H.Yu, T. Gao and Sh.Y. Yang,"Comments on the Policies of Ecological Compensation in China,"Environmental Protection,Vol.19,Oct.2006,pp.38-43

[29] Y.F. Feng, Y.H. Liu, ,F. Wang and M.Sh. Yang, ” Progress of Ecological Compensation Practice in China,"Ecological Economy,Aug.2009,pp.85-88.109.

[30] Z.Q. Wang, Z.L. Wang,L.Zhang and Y.Sh .Su, "Study on Basic Legal Problems about Mechanism of Compensation for Ecology--Taking Protection for Diversity of Living Things in Nature Reserve of "Source of Three Rivers"as an Example,"China Population Resources and Environment, Vol.16,Jan. 2006,pp.101-107.

[31] W.G. Jia,"The Design of Forest Eco-compensation Mechanisms in the Construction of Green Jiangsu,”Journal of Shanxi Agricultural University(Social Science Edition,Vol.9,Apr. 2010,pp.457-460.

[32] Sh.R.Wu and Y.L. Gu,"Ractice International Forest Ecological Compensation and Effect Evaluation,"World Forestry Research, Vol.22,Apr. 2009,pp.11-16.

[33] L.Lai,x.j.Huang and W.L. Liu,"Advances in theory and methodology of ecological compensation,"Acta Ecologica Sinica, Vol.28,Jun.2008,pp.2870-2877.

[34] [34[H.L.Wei and L. Ge, "Study on Ecological Compensation of Nature Reserve," Environmental Protection,Feb.2008,pp.43-45.

[35] X.F.Yan and X.N. Ji," Study on the Later Stage Support of Ecological Resettlement in National Key Forest Ecological Functional Area," Theoretical Investigation, May.2014,pp.178-18. 